Volume-V, Issue-02, July-December, 2010

\title{
Making TeleTalk a Healthy Competitor among the Mobile Phone Operators in Bangladesh
}

\author{
MD. TAHIDUR RAHMAN ${ }^{1}$
}

\begin{abstract}
The people of Bangladesh are now dreaming of a digital Bangladesh. Fast development of telecommunications network is a must for the realization of the vision and aspiration of digital Bangladesh. Teletalk is the smallest in the sixoperator mobile phone market in Bangladesh having only 1.07 million subscribers and $2.04 \%$ market share. The present Teletalk is far away from its objectives, mission, and vision. Therefore, the main objective of this study is to analyze Teletalk and offer some suggestions to make it a healthy competitor among the mobile phone operators. The main strength of Teletalk is its domestic base and government ownership that encourages patriotic people to use TeleTalk. But bad network is its main weakness, and GP, Banglalink and Warid are the threats for Teletalk because of their size and quality of service. In order to become competitive in such a situation Teletalk should advertise its native nature more and apply direct selling policy along with strengthening the network coverage.
\end{abstract}

\subsection{INTRODUCTION}

The people of Bangladesh are now dreaming of a digital Bangladesh. Faster development of telecommunications network coupled with improved quality of service in line with the national development is a must for the fulfillment of the vision and aspiration of digital Bangladesh and also to take her to a position of honor in the community of nations in the $21^{\text {st }}$ century. Mobile phone operators have been playing an important role in this regard. The telecommunications market in Bangladesh, particularly the mobile phone sector, is consisted of six mobile phone operators. These are Grameen Phone Ltd. (GP), Axiata (Bangladesh) Limited (Aktel), Orascom Telecom Bangladesh Limited (Banglalink), PBTL (Citycell), Teletalk Bangladesh Ltd. (Teletalk), and Warid Telecom International L.L.C (Warid). Among the mobile phone operators, Norwegian Grameen phone, which started its journey in 1997 in Bangladesh, is the leader having the highest market share of $44.36 \%$. Citycell, the first mobile phone operator in Bangladesh, has been

\footnotetext{
${ }^{1}$ Senior Lecturer, Department of Business Administration, Northern University Bangladesh
} 
defeated (in terms of market share) by Grameen phone due to the Grameen's welltimed and effective business strategy. Banglalink is competing in the market as the second largest operator, though it started (in 1999) later than some other operators.

Among the mobile phone operators in Bangladesh, Teletalk is the only domestic and state-owned operator which was incorporated on December 26, 2004 as a public limited company under the Companies Act, 1994 with an authorized capital of Tk.2000 core. On the same day the Company obtained Certificate of Commencement of Business ${ }^{2}$. Teletalk Bangladesh limited was established with a view to achieving some objectives such as (1) to provide mobile telephone service to the people from the public sector, (2) to ensure fair competition between public and private sectors and thereby to safeguard public interest, (3) to meet a portion of unmitigated high demand of mobile telephone, and (4) to create a new source of revenue for the government. But still, Teletalk is the country's smallest operator having only 2.04 percent market share. Inspiring high hopes, it started operating in 2005 , but failed to compete with the five other operators due to poor quality of services and inappropriate marketing strategy ${ }^{3}$.

\subsection{OBJECTIVE OF THE STUDY}

The reasons behind establishing Teletalk were to ensure fair competition between public and private sectors and thereby to safeguard public interest and to create a new source of revenue for the government. The Mission of Teletalk is to innovate and constantly find new ways to enhance the services to its customer's current needs and desires for the future. The vision of Teletalk is to know its customers and meet their needs better than any one else ${ }^{4}$. But the present Teletalk is far away from all of its objectives, mission, and vision. Therefore, the main objective of this study is to analyze the strengths, weaknesses, opportunities, and threats (SWOT) of the state-owned mobile phone operator Teletalk and to offer some suggestions that may become helpful in making it a healthy competitor among the mobile phone operators in Bangladesh. Some other related objectives are:

- to analyze the current scenario of mobile telephony service in Bangladesh and

- $\quad$ to analyze the customers' possession and attitude towards Teletalk

\footnotetext{
2 Teletalk Annual Report 2006, p.7.

${ }^{3}$ hasan@thedailystar.net, Sunday, September 14, 2008, retrieved from http://priyo.com.

${ }^{4}$ Official website of Teletalk, retrieved on January 20,2010 from, http://www.teletalk. com. bd
} 


\subsection{LITERATURE REVIEW}

Making a losing concern into a profitable one or a weak one into a strong one is not an easy task. It is difficult because it requires proper implementation of a number of strategic decisions. SWOT analysis facilitates policy makers widening the eyes and choosing the effective strategies. A SWOT analysis is a process to identify where you are strong and vulnerable -- where you should defend and attack. The result of the process is a 'plan of action', or 'action plan'. Sizing up a firm's resource strengths and weaknesses and its external opportunities and threats, commonly known as SWOT analysis, provides a good overview of whether a firm's business position is fundamentally healthy or unhealthy (Aurther \& Strickland, 2004). SWOT analysis is more than an exercise of making four lists. The really valuable part of SWOT analysis is determining what story the four lists tell about the company's situation and thinking about what actions are needed. Understanding the story involves evaluating the strengths, weaknesses, opportunities, and threats and drawing conclusions about (1) how the company's strategy can be matched to both its resource capabilities and its market opportunities, and (2) how urgent it is for the company to correct which particular resource weaknesses and guard against which particulars external threats (Duncan Jack \& et al., 1998).

The first step of the actual implementation of the balanced scorecard is to clarify the company vision and strategy. By first implementing the SWOT analysis, to develop a set of strategies that makes sense, will serve as a stepping stone towards the actual implementation of the balanced scorecard (Kaplan \& Norton, 1996). The overall evaluation of a company's strengths, weaknesses, opportunities, and threats is called SWOT analysis. Once the company has performed a SWOT analysis it can proceed to develop specific goal for the planning period (Kotler, 2003).

SWOT is often used as part of a strategic planning process. It is a planning tool used to understand the Strengths, Weaknesses, Opportunities, and Threats involved in a project or in a business. It involves specifying the objective of the business or project and identifying the internal and external factors that are favorable or unfavorable in achieving that objective (Menon \& et al., 1999). As part of the development of strategies and plans to enable the organization to achieve its objectives, the organization will use a systematic/rigorous process known as corporate planning. SWOT alongside PEST (political, economic, social, and technological factors) can be used as a basis for the analysis of business and environmental factors (Armstrong, 2006). SWOT is used to look for gaps and matches between competences and resources and the business environment (Wheelan \& Hunger, 1998). Yet, according to Hill and Westbrook SWOT may harm performance (Hill \& Westbrook., 1997). 
The SWOT matrix clearly identifies the critical success factors that can be implemented into the identification of the different aspects toward the balanced scorecard (Lee \& Andrew, 2000).

\subsection{METHODOLOGY}

In order to identify and analyze the current conditions, particularly the strengths, weaknesses, opportunities, and threats of the state-owned mobile phone operator Teletalk and to make some suggestions, both primary and secondary data have been used. Secondary data have been collected from the company annual reports, daily news papers, and the web sites of the operators as well as Bangladesh Telecommunication Regulatory Board (BTRC). To collect primary data, a semistructured questionnaire having 15 questions was prepared and 450 mobile phone users were randomly selected and interviewed to know the external factors such as the customers' possession, preference in using mobile phone operator, and attitude towards Teletalk. After scrutinizing, 400 questionnaires were selected as sample size. Then, using the statistical software, SPSS, the survey results have been analyzed and categorized as strengths, weaknesses, opportunities, and threats of Teletalk. Percentile, mean, variance, standard deviation and some other statistical tools have been used in the analysis. Finally, combining the elements (SWOT) the researcher has made some recommendations for the development of the state-owned and weakest Teletalk.

\subsection{A SYNOPSIS OF THE MOBILE PHONE OPERATORS IN BANGLADESH}

Mobile phone, a renaissance invention for modern telecommunication, started its journey in Bangladesh in 1989. That year, Bangladesh Telecom Limited (BTL) was awarded a license to operate cellular, paging, and other wireless communication networks. Then in 1990 Hutchison Bangladesh Telecom Limited (HBTL) was incorporated in Bangladesh as a joint venture between BTL and Hutchison Telecommunications (Bangladesh) Limited. HBTL began commercial operations in Dhaka using the AMPS mobile technology in 1993 and became the 1st cellular operator in South Asia.

Later that year Pacific Motors bought 50\% of BTL. By 1996 HBTL was renamed as Pacific Bangladesh Telecom Limited (PBTL) and launched the brand name "Citycell Digital" to market its cellular products. Citycell provides its services using the CDMA technology. The current market leader GP started its journey in 1997 using the GSM technology as the second mobile phone operator. In the same year Aktel also started operation in Bangladesh. Banglalink, Teletalk, and Warid 
started their journey later. All the operators except Citycell use GSM technology in providing their services. At present there are six mobile phone operators in Bangladesh. In addition to these six there are some locally operating mobile phone operators in Bangladesh like Dhaka phone, Rangstel, etc. The total number of Mobile Phone Active Subscribers reached 52.43 million at the end of December 2009. The number was 27.72 million about two and a half years back. Besides telephony service, mobile phone companies in Bangladesh are offering a number of services. Services of Mobile phone operators are: Voice call, Internet, SMS, Voice SMS, MMS, Welcome Tune, Voice Mail Services (VMS), SMS Push pull services, Fax, Bill pay, Cell bazaar, Instant Messaging, SMS based alerts/services, Music, Cricket updates, Web SMS, Mobile Backup, etc.

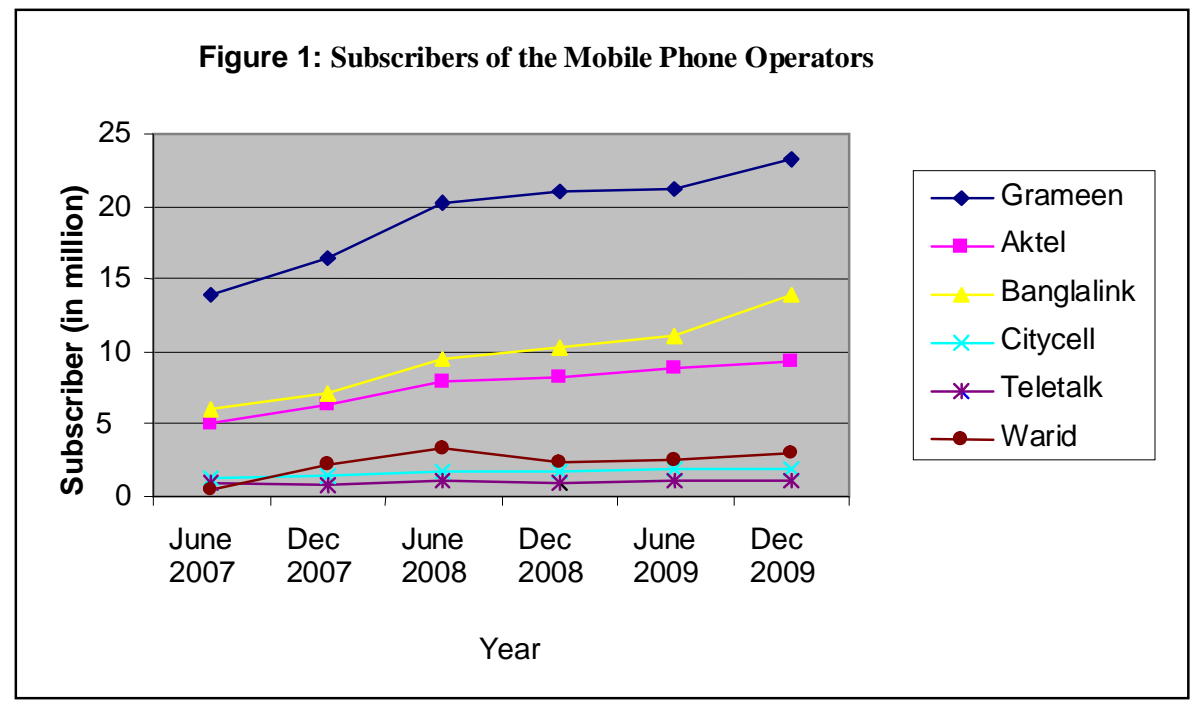

Source: BTRC Website ${ }^{5}$

\subsection{FINDINGS AND DISCUSSION}

Out of the 400 respondents, 245 were students, 83 service holders, 41 business men, and the remaining 31 respondents were of various other types (retired, housewife, etc.).The findings of the study have been categorized and presented under four heads namely Strengths, Weaknesses, Opportunities, and Threats of Teletalk. The following matrix shows that the strengths and weaknesses are a firm's

${ }^{5}$ Official Web Site, BTRC, retrieved on January 20, 2010 from http://www.btrc.gov.bd 
internal matter, whereas the opportunities and threats come from external environment. Strengths and opportunities are positive for a firm while weaknesses and threats are negative or potential to be negative for a firm. The internal factors are within the control of organization, such as operations, finance, marketing and other areas. On the contrary, the external factors are out of the organization's control, such as political and economic factors, technology, competition, and other areas.

The SWOT Matrix Model

\begin{tabular}{||c||c||c||}
\hline \hline \multirow{3}{*}{} & \multicolumn{2}{|c||}{ Internal } \\
\cline { 2 - 3 } & Strengths & Weaknesses \\
\cline { 2 - 3 } & Opportunities & Threats \\
\cline { 2 - 3 } & \multicolumn{2}{|c|}{ External } \\
\cline { 2 - 3 } & \multicolumn{3}{|c|}{} \\
\cline { 2 - 3 } & \multicolumn{2}{|c|}{} \\
\hline
\end{tabular}

Being aware of the above model, the strengths, weaknesses, opportunities and threats of Teletalk are presented as follows:

\subsection{Strengths of Teletalk}

Strengths are positive tangible and intangible attributes, internal to an organization. Although Teletalk is an underdog among the mobile phone operators in Bangladesh, the following strengths have been found in it from the research:

- The most important strength of Teletalk is that the company is fully domestic and government-owned whereas all other operators, except for GP of which $38 \%{ }^{6}$ share is owned by domestic Grameen Telecom, are fully owned by foreigners. About $87.80 \%$ (Table-4) respondents who use Teletalk explained patriotism as the reason for their use of Teletalk beside some other reasons.

- The customers' perception towards Teletalk is very positive. About $14.5 \%$ (Table-7) of the respondents own Teletalk SIM and use it as first choice, second choice or part-time basis (some of these are also unused). But $51.75 \%$ (which is $44.30 \%$ of total users, (Table- 8 ) of the respondents who do not use Teletalk strongly agree to use Teletalk if it provides better service. Where as only $2.80 \%$ of the respondents answered that they would

\footnotetext{
${ }^{6}$ Grameenphone Official site, retrieved on January 1, 2010 from http://www.grameenphone.com.
} 
not use Teletalk. This positive attitude toward it is one of the major strengths of Teletalk.

- It has been found that those who know about the ownership of Teletalk, being motivated by patriotism, are the major users of Teletalk. Among the respondents, $48.30 \%$ (Table-5) know accurately about the domestic and government ownership of Teletalk whereas $37.3 \%$ only know that it is domestic, which is also a strength of Teletalk.

- The rate which is applied in T\&T call from Teletalk is lower as compared to any other operator in Bangladesh. The call rate applicable within the same operator and with other operator is also reasonable.

\subsection{Weaknesses of Teletalk}

Weaknesses are factors that are within an organization's control and that detract from its ability to attain the desired goal. Our research has revealed a number of weaknesses of Teletalk Bangladesh Limited which are shown below:

- The great weakness of Teletalk is that the company's network coverage is very poor as compared to that of others. According to the company website, Teletalk has established network in 64 Districts, 402 Upazilas, and most of the highways, but its availability and quality is very poor as compared to GP and Banglalink. $86.20 \%$ (Table-10) of the respondents (who use Teletalk) mentioned bad network as the main problem of Teletalk. Whereas $54.09 \%$ (Table-7) of the respondents who use other than TeleTalk SIM have mentioned bad network as the reason for their not using Teletalk.

- Its current market share is very low; only $1.07(2 \%)$ million (Figure-1\&2) subscribers at the end of December 31,2009, which was 1.10 million at the end of June 302009 and 1.07 million at the end of December 31, 2008. This indicates a stable or falling trend in the number of users.

- Our research has found that only $2.06 \%$ (Table-2) of total users use Teletalk as their first choice which is $63.8 \%, 13.3 \%$, and $10.5 \%$ in case of GP, Banglalink, and Warid respectively. Therefore, the cash inflows, net income and balance sheet condition of Teletalk are very poor.

- GP, Banglalink and some other operators entered the market earlier than Teletalk, and captured majority of the solvent customers (those who spend large amount daily). Teletalk does not enjoy this early-entry benefit. When the respondents were asked about the reason of not using Teletalk, 50.8 \% (Table-7) of the respondents replied that they have already bought other SIMs and are reluctant to change them now. 
- The promotional activities of Teletalk are very poor and ineffective in marketing its brand which is very high in the case of non-domestic operators such as GP and Banglalink. For this reason the users (present and prospective) are not well conversant with the products and services of Teletalk. When the respondents were asked about the promotional activities of Teletalk, 45.3\% (Table-9) commented that they are very poor, 34\% commented as rare and ineffective, $3.8 \%$ commented as sufficient, and $17 \%$ didn't comment at all.

Figure 2: Current Market Share of the Operators

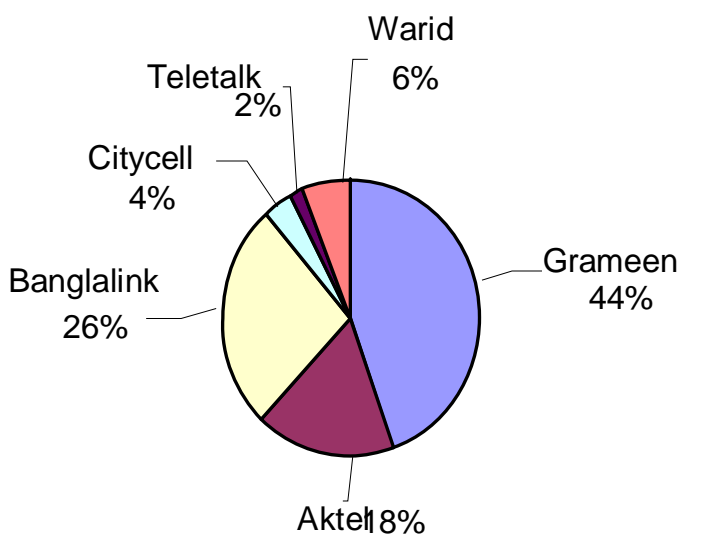

Source: BTRC Website

- Around 4.5 million customers now enjoy internet services, of which 90\% are connected through the mobile phone operators' wireless modems ${ }^{7}$. The internet penetration rate in the country widened to 4 percent from a mere 0.4 percent three years ago (BTRC Website). Teletalk has also internet facilities which are known by only 13\% (Table-6) users but the percentages are $93.5 \%, 53.25 \%$, and $45.5 \%$ in the case of GP, Citycell, and Banglalink respectively. This indicates the lack of promotional activities of Teletalk.

- Teletalk is now at introduction stage of its life cycle. Therefore, it needs high investment in infrastructural development activities and due to this reason their

\footnotetext{
${ }^{7}$ The Daily Star, Sunday, October 01, 2009, retrieved on January 25, 2010
} 
cash inflows are very low as compared to cash outflows. This creates liquidity problem, which is a major weakness of Teletalk.

- Most of the high officials of Teletalk are bureaucrats and they do not have any direct benefit if Teletalk performs well. Due to the bureaucratic problems Teletalk generally takes more time to implement its decisions. $17.6 \%$ of the respondents think bureaucratic problems as one of the reasons behind the backwardness of Teletalk.

- The customer care centers and recharge centers of Teletalk are not available. Moreover, their customer care centers remain closed after 5 p.m everyday, after 2 p.m every Saturday, and fully on Fridays. On the other hand, the customer care centers of some other competitors remain open twenty four hours. Among the respondents who use Teletalk, 52.23\% (Table-10) have commented that they face unavailability problem in recharging their accounts and getting other problems solved.

- Talented, dynamic, and devoted employees are very essential for a company's growth. But Teletalk is unable to attract and retain talented employees due to their unattractive payment structure as compared to others.

- In most of the cases Teletalk does not give any previous message of interruption in service. Even after a severe interruption in telephone service, they do not apologise to customers (e.g. the two-day long interruption from January 30 to 31 of 2010). Sometimes Teletalk does some unnecessary work which is annoying instead of adding any value, such as, it gives three messages after recharging the account, where only one message is enough.

\subsection{Opportunities of Teletalk}

We shift our focus to external factors when we look at opportunities. Here we try to identify areas of business we think the company is looking to enter, or should be looking to enter. We also look for opportunities to gain market share from competitors. The opportunities of Teletalk are described below:

- About $14 \%$ of the respondents think that financial weakness is one of the reasons for the backwardness of Teletalk. Share market is one of the important sources of long-term financing. And it can be utilized to collect necessary fund by issuing shares or bond.

- It has been found that those who know about the ownership of Teletalk are the main users of it. Teletalk is a fully domestic and state owned company, but only $48.3 \%$ respondents know this and $12.3 \%$ respondents are not yet 
sure about the ownership of Teletalk. If Teletalk can convey their native and government ownership to users, the use of its SIM will increase.

- It has been found that the mean of SIM a user own, is 2.14 (Table-1) for students 1.85 for service holders, 1.87 for business people, and 1.42 for others. And the standard deviations are 1.12, 0.96, 0.91, and 0.56 respectively. This indicates that the youth, especially college and university students, are more vulnerable (in term of switching from one operator to another) than any other users. Therefore, Teletalk should emphasize to cater this section of users.

- Establishing towers requires large investment. BTTB has telephone network and towers in almost every Thaana in Bangladesh. Adding some equipment to this facility Teletalk can economically expand its network coverage which is a costly job for any other operators. This is a great opportunity for Teletalk.

- The Bangladesh Government allows Sonali Bank Limited for different government payments which are a source of earning for the bank. Likewise, the government can permit only Teletalk for different government bills payment such as gas bill, electricity bill, job application, admission test etc., which will obviously enhance its use.

- The use of internet modem or SIM is growing very fast. About $25 \%$ of the internet users use net with their mobile phone or through internet modem with PCs and most of the users are students. Therefore, Teletalk can concentrate on selling internet modem or Internet SIM.

- Offering a very cheap rate like T\&T call rate Teletalk can provide its SIM with handset to government employees and make it mandatory to use. It will enhance the use of Teletalk.

\subsection{Threats Faced by Teletalk}

Threats are external factors, beyond an organization's control, which could place the organization mission or operation at risk. The entrance of new competitors, slow market growth, increased bargaining power of key buyers or suppliers, technological changes, and new or revised regulations could appear as threats to a firm's success. Therefore, it is important to do a good threat analysis. Some possible threats faced Teletalk are:

- The financial strengths, network coverage, and promotional activities with which GP, Banglalink and other operators are running their activities are remarkable and many times better than Teletalk. This is a major threat for Teletalk if it wants to attract new customers. 
- GP, the strongest operator in Bangladesh, has already collected TK 450 crore from the country's share market. Some other operators (e.g. Banglalink) are also trying to do this. If they (GP, Banglalink, etc.) use all this money for their network expansion and technological development the small operators like Teletalk will then be out of market.

- Indian telecom giant Airtel has bought the majority ownership of another competitor Warid which has alread won the mind of young people due to its attractive call rates, internet facilities and other services. It is hoped that the change in ownership will strengthen the performance of Warid. If it is so, it will shorten the market share of Teletalk.

- The market share of the competitors of Teletalk is very high. Therefore, their cash inflows, profits, and financial strengths are very strong as compared to Teletalk. Due to the financial strength it would be easier for the strong operators to adopt new technology and services which will attract the customers' attention. Therefore the market share of Teletalk may be hampered.

- Another competitor Aktel has made an agreement with GP to use each other's network facilities. This will facilitate GP and Aktel to expand their network coverage and ultimately it will increase the number of customers and their satisfaction. Since Teletalk hasn't made any such deal it will create large gap between Teletalk and others in terms of network.

\subsection{CONCLUSION AND RECOMMENDATIONS}

The wizardry of SWOT is the matching of specific internal and external factors, which creates a strategic matrix and which makes sense. According to Weihrich (1982), possible combinations are: maxi-maxi (strengths/opportunities), maxi-mini (strengths/threats), mini-maxi (weaknesses/opportunities), and mini-mini (weaknesses/threats). Maxi-maxi (S/O) combination suggests that an organization should strive to maximize its strengths to capitalize on new opportunities. Maximini (S/T) combination suggests that an organization should strive to use its strengths to minimize threats. Mini-maxi (W/O) combination emphasizes to conquer the organization's weaknesses by making the most of any new opportunities. Minimini (W/T) combination suggests adopting, most definitely, defensive strategy to minimize an organization's internal weaknesses and avoid external threats. Considering the above combination rules our recommendations toward Teletalk are as follows:

- The company's network capacity is the poorest among the operators. Therefore, the Company must take immediate actions so as to expand its 
network coverage. To expand the network capacity Teletalk can use the towers of other operators through negotiation like (Aktel and GP) where Teletalk's network is not available. The following recommendations will be fruitful only if this recommendation is implemented without delay.

- The image value of Teletalk is very poor. That is why, the possibility of people's buying Teletalk SIM is also poor. Besides most of the users who have two or more SIMs, are not willing to buy any more. Therefore, the company should apply direct selling policy from door to door and at different university/college campuses and offices to sell their SIM.

- To foster the promotional activities, it can gift SIM with handset to Media personalities and freedom fighters and their oral commitments about the use of domestic and government owned mobile phone can be advertised in TV and newspapers. This will also help increase the number of subscribers.

- Wireless internet service by mobile phone operators has become a craze among the youth, especially university and college going students. Mobile phone operators including all other internet service providers (ISPs) take this facilities from Bangladesh Submarine Cable Company Ltd (BSCCL), another state owned company. Taking some special facilities from BSCCL Teletalk can market its internet facility (including internet modem).

- Many public sector companies are performing better than previous after enlisting themselves in the stock exchange. Teletalk can enlist itself in the stock exchange by issuing shares or bond. This will provide Teletalk the required fund for expansion and quality service. This may enhance the performance of the company as well.

- The telecom regulator has announced that it will issue 3G ( $3^{\text {rd }}$ Generation) technology license as early as possible. $3 \mathrm{G}$ is a technology that includes capabilities and features such as enhanced multimedia (voice, data, video, and remote control), usability on all popular modes (cellular telephone, email, paging, fax, videoconferencing and Web browsing) and broad bandwidth and high speed. TeleTalk have a plan to adopt 3G (3rd generation) technology. Before giving license to all other operators this license should be given to Teletalk first as a test case which will facilitate the use of Teletalk among the users.

- To cater the young generation, the most vulnerable group of customers, Teletalk should offer and advertise a youth based and economic mobile to mobile connectivity like GP's Djuice, Banglalink's Desh, etc.

- This is a government owned company. Therefore, the government can help its growth by imposing some restrictions on competitors and relaxing some rules 
for Teletalk. As for example, DESA Load shedding push-pull service is a unique service provided only by Teletalk. If there are any more opportunities of government organizations available, they should be restricted only to Teletalk.

- The regulator, BTRC, must enforce a level playing field for the sake of fair competition and existence in the long run. It is because big operators in the market enjoy advantages for their size and potential anti-competitive nature.

- A large number of the leading organizations in our country provide corporate SIM to their employees and make it mandatory to use. Teletalk can go for a contract with the Government. of Bangladesh to provide SIM at a reduced call rate to government employees in the areas where the network of Teletalk is available. This will ultimately increase the number of users.

- Though Teletalk is a Public Limited Company, there are some bureaucratic problems in implementing the policy decisions. It is because the directors do not have any direct return or benefits if the Teletalk does well. To overcome this problem, directors should be taken from the owners (share holders) after offloading shares.

- To enhance the bonding between the devotees (users) and the company, the messages about interruption of service should be given early enough. If it fails to do so, the company should at least send messages apologizing for the interruption.

- Teletalk should apply process reengineering. Under process reengineering all the activities of a company are analyzed and non-value added activities are eliminated from the process. As for example, it can send one message instead of three after recharging.

If the aforementioned recommendations can be implemented as early as possible, the corporate image will be enhanced, customers will be satisfied, their confidence on Teletalk will be reinstate and ultimately the company will be a healthy competitor among the mobile phone operators in Bangladesh.

\section{REFERENCES}

Armstrong, M. (2006), A Handbook of Human Resource Management Practice, 10th edition, Kogan Page, London, p. 682.

Duncan Jack W. et al. (1998), Comparative Advantage and Internal Organizational Assessment, Academy of Management Executive, 12 (3), pp.6-16.

Hill, T. \& Westbrook., R. (1997), SWOT Analysis: It's Time for a Product Recall, Long Range Planning-International Journal of Strategic Management, London, 30 (1), pp. 46-52. 
Kaplan, R.S., Norton, D.P. (1996), “The Balanced Scorecard: Translating Strategy into Action" Harvard Business School Press, Cambridge, pp.22-43.

Kotler, P. (2003), Marketing Management, $11^{\text {th }}$ Edition, Prentice-Hall International, Inc, New Jersey, pp. 102-105.

Lee S.F, Andrew Sai On Ko. (2000), "Building Balanced Scorecard with SWOT analysis, and implementing "Sun Tzu's The Art of Business Management Strategies" on QFD Methodology", Managerial Auditing Journal, 15(1/2), pp. 68-76.

Menon, A. et al. (1999), "Antecedents and Consequences of Marketing Strategy Making, Journal of Marketing”, 63, pp. 18-40.

Thompson, Aurther A. \& Strickland A. J. (2004), Strategic Management Concept and Cases, $14^{\text {th }}$ Edition, Tata McGraw-Hill Publishing Company Limited, New Delhi, p.117.

Weihrich, H. (1982), "The TWOS matrix - a tool for situational analysis", Journal of Long Range Planning, 15(2), p.96.

Wheelan, T.L. and Hunger, J. D. (1998), Strategic Management and Business Policy, 5th Edition, Addison-Wesley Longman, Essex, p.312.

APPENDIX

TABLE 1

PROFESSION -GENDER CROSS TABULATION \& DESCRIPTIVE STATISTICS OF NO. OF SIM

\begin{tabular}{l|cc|c|c|c|c|c}
\hline \multirow{2}{*}{ Profession } & \multicolumn{2}{|c|}{ Gender } & \multirow{2}{*}{ Total } & \multicolumn{5}{c}{ SIM Possession } \\
\cline { 2 - 3 } & Male & Female & & Mean & Variance & Std. Deviation & Std. Error \\
\hline Student & 172 & 73 & 245 & 2.14 & 1.262 & 1.124 & .072 \\
Service & 65 & 18 & 83 & 1.87 & .921 & .960 & .105 \\
Business & 40 & 01 & 41 & 1.83 & .845 & .919 & .144 \\
Others & 8 & 23 & 31 & 1.42 & .318 & .564 & .101 \\
Total & 285 & 115 & 400 & -- & -- & -- & - \\
\hline
\end{tabular}

TABLE 2

FIRST CHOICE OF THE USERS

\begin{tabular}{ll|c|c|c|c}
\hline & & Frequency & Percent & Valid Percent & Cumulative Percent \\
\hline Valid & GP & 255 & 63.8 & 63.8 & 63.8 \\
& Banglalink & 53 & 13.3 & 13.3 & 77.0 \\
& Aktel & 7 & 1.8 & 1.8 & 78.8 \\
Citycell & 22 & 5.5 & 5.5 & 84.3 \\
Teletalk & 21 & 5.3 & 5.3 & 89.5 \\
Warid & 42 & 10.5 & 10.5 & 100.0 \\
Total & 400 & 100.0 & 100.0 & \\
\hline
\end{tabular}


TABLE 3

SECOND CHOICE OF THE USERS

\begin{tabular}{ll|c|c|c|c}
\hline & & Frequency & Percent & Valid Percent & Cumulative Percent \\
\hline Valid & NA & 148 & 37.0 & 37.0 & 37.0 \\
& GP & 72 & 18.0 & 18.0 & 55.0 \\
& Banglalink & 81 & 20.3 & 20.3 & 75.3 \\
Aktel & 18 & 4.5 & 4.5 & 79.8 \\
Citycell & 19 & 4.8 & 4.8 & 84.5 \\
& Teletalk & 20 & 5.0 & 5.0 & 89.5 \\
& Warid & 42 & 10.5 & 10.5 & 100.0 \\
& Total & 400 & 100.0 & 100.0 & -- \\
\hline
\end{tabular}

TABLE -4

REASON OF USE/PREFERENCE

\begin{tabular}{ll|c|c|c|c}
\hline & Frequency & Percent & Valid Percent & Cumulative Percent \\
\hline Valid & F & 11 & 2.8 & 2.8 & 2.8 \\
& G & 112 & 28.0 & 28.0 & 30.8 \\
GF & 22 & 5.5 & 5.5 & 36.3 \\
GI & 25 & 6.3 & 6.3 & 42.5 \\
GIF & 5 & 1.3 & 1.3 & 43.8 \\
GP & 12 & 3.0 & 3.0 & 46.8 \\
I & 8 & 2.0 & 2.0 & 48.8 \\
L & 71 & 17.8 & 17.8 & 66.5 \\
LF & 24 & 6.0 & 6.0 & 72.5 \\
LG & 52 & 13.0 & 13.0 & 85.5 \\
LGF & 20 & 5.0 & 5.0 & 90.5 \\
LGI & 10 & 2.5 & 2.5 & 93.0 \\
LGP & 7 & 1.8 & 1.8 & 94.8 \\
LI & 4 & 1.0 & 1.0 & 95.8 \\
LP & 12 & 3.0 & 3.0 & 98.8 \\
P & 5 & 1.3 & 1.3 & 100.0 \\
Total & 400 & 100.0 & 100.0 &
\end{tabular}

$\mathrm{F}=$ FnF, G=Good Network, I=Image value, L=Lower Rate, $\mathrm{P}=$ Patriotism 
TABLE -5

USERS' KNOWLEDGE ABOUT THE OWNERSHIP OF TELETALK

\begin{tabular}{lccccc}
\hline & Frequency & Percent & Valid Percent & Cumulative Percent \\
\hline Not Sure & 49 & 12.3 & 12.3 & 12.3 \\
Govt. \&Domestic & 193 & 48.3 & 48.3 & 60.5 \\
Domestic only & 149 & 37.3 & 37.3 & 97.8 \\
Partly Dom. & 6 & 1.5 & 1.5 & 99.3 \\
Foreign & 3 & .8 & .8 & 100.0 \\
Total & 400 & 100.0 & 100.0 & -- \\
\hline
\end{tabular}

TABLE -6

WHETHER TELETALK HAS INTERNET FACILITY

\begin{tabular}{cl|c|c|c|c}
\hline & & Frequency & Percent & Valid Percent & Cumulative Percent \\
\hline \multirow{4}{*}{ Valid } & No & 300 & 87.0 & 87.0 & 87.0 \\
& Yes & 53 & 13.0 & 13.0 & 100.0 \\
& Total & 400 & 100.0 & 100.0 & \\
\hline
\end{tabular}

TABLE -7

WHY NOT TELETALK

\begin{tabular}{ll|c|c|c|c}
\hline & Frequency & Percent & Valid Percent & Cumulative Percent \\
\hline NA & 58 & 14.5 & 14.5 & 14.5 \\
B & 94 & 23.5 & 23.5 & 38.0 \\
BC & 8 & 2.0 & 2.0 & 40.0 \\
BO & 54 & 13.5 & 13.5 & 53.5 \\
BU & 15 & 3.8 & 3.8 & 57.3 \\
Valid & 6 & 1.5 & 1.5 & 58.8 \\
BUC & 6 & 2.0 & 2.0 & 60.8 \\
C & 7 & 1.8 & 1.8 & 62.5 \\
O & 134 & 33.5 & 33.5 & 96.0 \\
U & 8 & 2.0 & 2.0 & 98.0 \\
UO & 8 & 2.0 & 2.0 & 100.0 \\
Total & 400 & 100.0 & 100.0 & -- \\
\hline
\end{tabular}

$\mathrm{NA}($ Teletalk user $)=58$, Non-user=342, $\mathrm{B}=\mathrm{Bad}$ network, $\mathrm{C}=$ High Call Rate, $\mathrm{O}=$ Bought Other SIM First, U=Unavailability of SIM, customer care center, and recharge center. 
TABLE -8

WHETHER USE TELETALK OR NOT, IF IT PROVIDES BETTER SERVICE

\begin{tabular}{ll|c|c|c|c}
\hline & Frequency & Percent & Valid Percent & Cumulative Percent \\
\hline \multirow{4}{*}{ Valid } & 58 & 14.5 & 14.5 & 14.5 \\
& NA & 177 & 44.3 & 44.3 & 58.8 \\
& Yes, of Course & 11 & 2.8 & 2.8 & 61.5 \\
& No & 154 & 38.5 & 38.5 & 100.0 \\
& Think Later & 400 & 100.0 & 100.0 & -- \\
\hline
\end{tabular}

TABLE -9

USERS' OPINION ABOUT PROMOTIONAL ACTIVITIES OF TELETALK

\begin{tabular}{clccccc}
\hline & & Frequency & Percent & Valid Percent & Cumulative Percent \\
\hline \multirow{6}{*}{ Valid } & No Comment & 68 & 17.0 & 17.0 & 17.0 \\
& Very Weak & 181 & 45.3 & 45.3 & 62.3 \\
& Rear \&Ineffective & 136 & 34.0 & 34.0 & 96.3 \\
& Sufficient & 15 & 3.8 & 3.8 & 100.0 \\
& Total & 400 & 100.0 & 100.0 & -- \\
\hline
\end{tabular}

TABLE -10

PROBLEMS OF TELETALK

\begin{tabular}{cl|c|c|c|c}
\hline & & Frequency & Percent & Valid Percent & Cumulative Percent \\
\hline \multirow{2}{*}{ Valid } & NA & 342 & 85.5 & 85.5 & 85.5 \\
& B & 22 & 5.5 & 5.5 & 91.0 \\
& BC & 3 & .8 & .8 & 91.8 \\
& BU & 19 & 4.8 & 4.8 & 96.5 \\
& BUC & 6 & 1.5 & 1.5 & 98.0 \\
& C & 1 & .3 & .3 & 98.3 \\
& U & 7 & 1.8 & 1.8 & 100.0 \\
& Total & 400 & 100.0 & 100.0 & \\
\hline
\end{tabular}

N/A=Non-user of Teletalk (342), User $=58, \mathrm{~B}=$ Bad network, $\mathrm{C}=$ Costly, $\mathrm{U}=$ Unavailability of recharge center and customer care centers

TABLE -11I

DESCRIPTIVE STATISTICS OF MOBILE BILL

\begin{tabular}{lcc|c|c|c|c|c}
\hline \multicolumn{1}{c|}{ Profession } & Mean & Variance & Std. Deviation & Minimum & Maximum & Std. Error \\
\hline Student & 563.63 & $2,36,602.73$ & 486.42 & 50 & 3,500 & 31.08 \\
Service & 700.90 & $197,567.77$ & 444.49 & 50 & 2,200 & 48.789 \\
Business & 862.20 & 352847.56 & 594.01 & 200 & 3000 & 92.769 \\
Others & 374.03 & 62070.70 & 249.14 & 50 & 1000 & 44.747 \\
\hline
\end{tabular}

